\title{
The Importance of Improving the Quality of Care Among HIV/AIDS Hospitalizations in Portugal
}

\author{
Ahmed N. Shaaban ${ }^{1,2 *}$ and Maria Rosario O. Martins ${ }^{1}$ \\ 1 Global Health and Tropical Medicine, Institute of Hygiene and Tropical Medicine, NOVA University of Lisbon, Lisbon, \\ Portugal, ${ }^{2}$ EPIUnit-Instituto de Saúde Pública, Universidade Do Porto, Porto, Portugal
}

Keywords: HIV/AIDS, quality of care (measurement), length of stay (LOS), 30-day readmission, hospital performance indicators

\section{OPEN ACCESS}

Edited by:

Sandra C. Buttigieg,

University of Malta, Malta

Reviewed by:

Paula Odete Fernandes,

Polytechnic Institute of

Bragança, Portugal

*Correspondence:

Ahmed N. Shaaban

anshaaban@brandeis.edu

Specialty section:

This article was submitted to

Health Economics,

a section of the journal

Frontiers in Public Health

Received: 13 February 2019

Accepted: 30 August 2019

Published: 13 September 2019

Citation:

Shaaban AN and Martins MRO (2019)

The Importance of Improving the

Quality of Care Among HIVIAIDS

Hospitalizations in Portugal.

Front. Public Health 7:266.

doi: 10.3389/fpubh.2019.00266
HIV affects almost 37.9 million persons globally, and an estimated 1.7 million new HIV infections occur in 2018 (1). While HIV/AIDS is taking a devastating toll on populations' health, lives and families, the disease is imposing a serious economic burden on governments (2-4) being classified as the greatest single financial burden on healthcare systems globally (5). This burden is predominantly due to the high payments of antiretroviral therapy (ART), hospitalizations, and associated opportunistic infections treatment $(6,7)$. In Portugal, HIV continues to be a major public health concern and HIV prevalence is among the highest in Europe $(8,9)$ with 41,000 individuals who are living with HIV, representing $0.5 \%$ of the total population (10) (see Table 1 for an informative overview of HIV/AIDS in Portugal). The country also still records annual rates of new HIV/AIDS diagnosis, which have been classified among the highest in the European Union (EU) (8). Admissions among HIV/AIDS patients still pose considerable challenges to the Portuguese national health system $(5,11)$. In Portugal, hospitalizations related to HIV/AIDS are some of the most expensive with an average daily cost of $€ 825$ and an average length of stay of 23 days, placing HIV/AIDS as the second greatest Major Diagnostic Category (MDC) $(5,12)$. In addition, and after the financial crisis that hit Portugal in 2011, the country went through strict fiscal austerity that resulted in budget cuts, reduction of spending on sensitive health sectors, and restructuring numerous public entities including the National AIDS Program (NAP) (12-14). It is important to know that the average cost of HIV treatment in Portugal is about $14,000 € /$ patient per year (6). The main cost driver is the antiretroviral medications $(€ 9,598)$, followed by hospitalizations $(€ 1,323)$. Treatment costs grow with the severity of disease from $€ 11,901$, with a CD4 count more than 500 , to $€ 23,351$, with a CD4 count $<50$ (6). In other words, while cost related to antiretroviral remains constant over the course of the disease, the cost progression remains mainly linked to the associated hospitalizations and admissions related to HIV. Moreover, the shift of HIV infection from a fatal disease into a chronic illness carries substantial challenges to the health system. The introduction of antiretroviral therapy (ART) has dramatically increased the life expectancy of HIV patients (1517). This modification in the natural evolution of HIV infection has led to a substantial increase in the financial burden and cost due to the net increase in the number of people living with HIV and the associated life-long treatment and comorbidities $(16,18)$. 
TABLE 1 | HIV/AIDS estimates in Portugal.

Adults aged 15 and over living with HIV

41,000 (Cl: 36,000-46,000)

Adult aged 15-49 HIV prevalence rate

0.5 (Cl: $0.4-0.5)$

HIV incidence per 1,000 population (adults 15-49)

People living with HIV who are on ART

0.10

37,000

Percent of people living with HIV who are on ART

Average cost of HIV treatment per year

90 (Cl: 78-95)

$14,277 € /$ patient*

Sources: UNAIDS, *Perelman et al. (6).

$\mathrm{Cl}$, Confidence Interval.

In this context, one possible solution to overcome this associated economic burden is to increase value in healthcare by integrating quality measures of hospitals' performance while reducing the costs of healthcare. Previous reviews supported the evidence that there is great potential for decreasing costs by targeting deficiencies in quality, and accordingly we can maximize the benefits given the available resources (19-24). Two important quality measures had obtained growing attention as a benchmark indicator for measuring hospital's performance, thirty-day readmission rate, and length of stay (LOS) (22, 25-28). However, despite being optimal methods for assessing hospital's performance, there remains a scarcity of research pertaining to the factors that can influence these quality indicators, especially when it comes to assessing hospitalizations among HIV/AIDS patients in Portugal. Thirty-day hospital readmission is defined as an episode in which a patient is readmitted within 30 days from the last discharge. Early readmission rates have increasingly been used as an outcome measure in health services research and as a quality benchmark for health systems (29-31). However, although often preventable, early readmissions have been recognized as frequent and costly events (32-34). For example, in the United States, one in five Medicare beneficiaries has 30-days readmission, with a cost of around $\$ 26$ billion per year $(34,35)$. Accordingly, hospital readmission rates were incorporated in the reimbursement decisions for several programs, in which the health systems penalize hospitals with higher than expected readmission rates $(33,36)$.

The second quality indicator is length of stay which is defined as the number of days a patient is hospitalized in relation to the admission diagnosis and it had been widely used to evaluate the effect of implementing patient group related reimbursement systems in the form of Diagnosis Related Groups systems (DRG) is length of stay $(37,38)$. This quality indicator has been recommended as an important outcome measure for quality improvement activities (28). Using length of stay as a hospital performance measure will allow us to impact cost and quality through payment incentives for hospitals or health care providers. For example, if a hospital reduces length of stay and accordingly the other associated resources and costs, the hospitals will be more efficient through maintaining a higher marginal return on each per admission payment (22).

The Portuguese national database of admissions among HIV patients can be obtained for research purposes from the Administration of the Health System (ACSS) (39). These data are anonymous, refers to the Diagnosis Related Groups (DRGs), and each record corresponds to a discharge episode and contains information collected while the patients were admitted to the hospital. These data include information about length of stay as well as information collected during the hospitalization that include socio-demographic characteristics (age, sex, region of residence), dates of hospitalization and discharge, Index hospitalization (admission type (urgent or scheduled), type of intervention (surgical or medical), type of diagnosis (primary and secondary diagnoses), type of procedures during the hospitalization), prior health care utilization (mode of transfer, destination after discharge), outcome at discharge (alive or deceased), coverage by the national health system (Yes/No). To determine 30-day readmission for each hospitalization, a unique fictional code included in the data can be used since it allows determining how many episodes correspond to the same user, in the same institution. This fictional code does not identify the user nor allow its identification afterward. Accordingly, readmission episodes and the time span between the readmission and the last discharge can be calculated for each hospitalization. accordingly, The variable of interest can be created as follows: Y $=0$ if hospitalizations without subsequent 30 -day readmission, $\mathrm{Y}=1$ if hospitalizations with subsequent 30 -day readmission(s). Univariate and multivariate logistic models can be estimated afterward to identify the determinants of hospitalizations with subsequent 30-day readmission.

Regarding length of stay, each hospitalization is associated with a record that refers to the number of days each person remains at hospital as a count data. However, giving the statistical nature of length of stay as count data, caution should be taken when handling such data with count distribution [for an informative overview of count distribution see (40)]. Using the most common techniques, namely the ordinary least squares (OLS) or logistic regression to handle a dependent variable with positive skewness as occurs in LOS, will violate the fundamental assumptions behind each technique $(41,42)$. Accordingly, this may result in biased and inefficient estimates and produce results that do not accurately reflect the observed data (41, 42). Fortunately, count statistical techniques (Poisson, negative binomial, Zero Inflated Poisson, and Zero Inflated Negative Binomial models) have been developed to handle count data on a dependent variable and can replace these suboptimal statistical strategies $(43,44)$. Using these count regression techniques will allow us to accurately determine the factors that can push length of stay further. Moreover, the conceptual and statistical advantages of each count model should be illustrated precisely since the accuracy and nature of results tend to vary depending on the specific model utilized.

This opinion contributes to the attempts on reducing the economic burden of HIV in Portugal, which is in line with Portugal's policy of cost reduction as a target to stabilize the economic situation. Our opinion point to other concerns that need to be considered: integration of quality measures as a method of evaluating hospitals' performance is crucial in the light of limited resources and should be considered as a national priority. A considerable work should be devoted to controlling and investigating the factors which tend to push 30-day 
admission rate and length of stay expenses further. The statistical nature of quality measures requires a deep understanding of the appropriate statistical models that should be used to avoid biased estimates. Finally, there is a potential in policy decision-making concerning the optimal use of limited resources and as a first step, we should deeply investigate the determinants of 30-days readmission and length of stay among HIV patients in Portugal.

\section{AUTHOR CONTRIBUTIONS}

AS conceived the work, reviewed literature, and wrote the manuscript. MM supervised the work and wrote the

\section{REFERENCES}

1. World Health Organization. HIV/AIDS Key Facts. (2019). Available online at: https://www.who.int/news-room/fact-sheets/detail/hiv-aids

2. Trapero-Bertran M, Oliva-Moreno J. Economic impact of HIV/AIDS: a systematic review in five European countries. Health Econ. Rev. (2014) 4:15. doi: 10.1186/s13561-014-0015-5

3. Ojo K, Delaney M. Economic and demograhic consequences of AIDS in Namibia: rapid assessment of the costs. Int $J$ Health Plan Manag. (1997) 12:315-26. doi: 10.1002/(SICI)1099-1751(199710/12)12:4<315::AIDHPM492>3.0.CO;2-A

4. Beck EJ, Miners AH, Tolley K. The cost of HIV treatment and care. Pharmacoeconomics. (2001) 19:13-39. doi: 10.2165/00019053-200119010-00002

5. Dias SS, Andreozzi V, Martins RO. Analysis of HIV/AIDS DRG in Portugal: a hierarchical finite mixture model. Eur J Health Econ. (2013) 14:715-23. doi: 10.1007/s10198-012-0416-5

6. Perelman J, Alves J, Miranda AC, Mateus C, Mansinho K, Antunes F, et al. Direct treatment costs of HIV/AIDS in Portugal. Rev Saúde Pública. (2013) 47:865-72. doi: 10.1590/S0034-8910.2013047004598

7. Hutchinson AB, Farnham PG, Dean HD, Ekwueme DU, Del Rio C, Kamimoto $\mathrm{L}$, et al. The economic burden of HIV in the United States in the era of highly active antiretroviral therapy: evidence of continuing racial and ethnic differences. J Acquir Immune Def Syndromes. (2006) 43:451-7. doi: 10.1097/01.qai.0000243090.32866.4e

8. Relatório Infeção VIH/SIDA - Situação em Portugal em 2017. (2018). Available online at: http://repositorio.insa.pt/bitstream/10400.18/5666/5/ INSA_Relatorio_VIH_e_SIDA_2017.pdf

9. Simões J, Augusto GF, Fronteira I, Hernández-Quevedo C. Portugal: Health system review. Health Syst Transit. (2017) 19:1-184. Available online at: http://www.euro.who.int/_data/assets/pdf_file/0007/337471/HiTPortugal.pdf?ua $=1$

10. UNAIDS. Country Factsheets: PORTUGAL. (2018). Available online at: https:// www.unaids.org/en/regionscountries/countries/portugal

11. Catumbela E, Freitas A, Lopes F, Mendoza MdCT, Costa C, Sarmento A, et al. HIV disease burden, cost, and length of stay in Portuguese hospitals from 2000 to 2010: a cross-sectional study. BMC Health Serv Res. (2015) 15:144. doi: 10.1186/s12913-015-0801-8

12. Dias SS, Martins MF. HIV AIDS length of stay outliers. Proc Comput Sci. (2015) 64:984-92. doi: 10.1016/j.procs.2015.08.617

13. Augusto GF. Cuts in Portugal's NHS could compromise care. Lancet. (2012) 379:400. doi: 10.1016/S0140-6736(12)60174-3

14. Karanikolos M, Mladovsky P, Cylus J, Thomson S, Basu S, Stuckler D, et al. Financial crisis, austerity, and health in Europe. Lancet. (2013) 381:1323-31. doi: 10.1016/S0140-6736(13)60102-6

15. Grinsztejn B, Luz PM, Pacheco AG, Santos DV, Velasque L, Moreira RI, et al. Changing mortality profile among HIV-infected patients in Rio de Janeiro, Brazil: shifting from AIDS to non-AIDS related conditions in the HAART era. PLoS ONE. (2013) 8:e59768. doi: 10.1371/journal.pone.0059768 manuscript. All the authors have agreed on the final version of the manuscript.

\section{FUNDING}

This study was funded by the Foundation for Science and Technology_FCT (Portuguese Ministry of Science, Technology and Higher Education) under the Department of Global Health and Tropical Medicine (GHTM) - The Portuguese Institute of Hygiene and Tropical Medicine (IHMT)-NOVA University of Lisbon (UNL); the Ph.D. Grants PD/BD/128066/2016 (AS) co-funded by FCT and the IHMT.

16. Quiros-Roldan E, Magoni M, Raffetti E, Donato F, Scarcella C, Paraninfo $\mathrm{G}$, et al. The burden of chronic diseases and cost-of-care in subjects with HIV infection in a Health District of Northern Italy over a 12-year period compared to that of the general population. BMC Public Health. (2016) 16:1146. doi: 10.1186/s12889-016-3804-4

17. Smith CJ, Ryom L, Weber R, Morlat P, Pradier C, Reiss P, et al. Trends in underlying causes of death in people with HIV from 1999 to 2011 (D: A: D): a multicohort collaboration. Lancet. (2014) 384:241-8. doi: 10.1016/S0140-6736(14)60604-8

18. Guaraldi G, Zona S, Menozzi M, Carli F, Bagni P, Berti A, et al. Cost of noninfectious comorbidities in patients with HIV. Clin Econ Outcomes Res. (2013) 5:481. doi: 10.2147/CEOR.S40607

19. Marshall M, Øvretveit J. Can we save money by improving quality? BMJ Qual Saf. (2011). 20:293-6. doi: 10.1136/bmjqs.2010.050237

20. Øvretveit J. Evidence: Does clinical coordination improve quality and save money? Volume 1: The Health Foundation; 2011.

21. Øvretveit J. Does Improving Care Coordination Save Money: A Review of Research. London: The Health Foundation (2011).

22. Aicher BO, Hanlon E, Rosenberger S, Toursavadkohi S, Crawford RS. Reduced length of stay and 30-day readmission rate on an inpatient vascular surgery service. J Vasc Nurs. (2019) 37:78-85. doi: 10.1016/j.jvn.2018. 11.004

23. Wani RJ, Tak HJ, Watanabe-Galloway S, Klepser DG, Wehbi NK, Chen LW, et al. Predictors and costs of 30-day readmissions after index hospitalizations for alcohol-related disorders in US adults. Alcoholism. (2019) 43:857-68. doi: 10.1111 /acer.14021

24. Riley K, Sulo S, Dabbous F, Partridge J, Kozmic S, Landow W, et al. Reducing hospitalizations and costs: a home health nutritionfocused quality improvement program. J Parenter Enteral Nutr. (2019). doi: 10.1002/jpen.1606. [Epub ahead of print].

25. Berry SA, Fleishman JA, Yehia BR, Korthuis PT, Agwu AL, Moore RD. Thirtyday hospital readmission rate among adults living with HIV. AIDS. (2013) 27:2059-68. doi: 10.1097/QAD.0b013e3283623d5f

26. Berenson RA, Paulus RA, Kalman NS. Medicare's readmissions-reduction program-a positive alternative. New Engl J Med. (2012) 366:1364-6. doi: 10.1056/NEJMp1201268

27. Kruse R, Hays H, Madsen R, Emons M, Wakefield D, Mehr D. Risk factors for all-cause hospital readmission within 30 days of hospital discharge. J Clin Outcomes Manag. (2013) 20:203-14.

28. Brasel KJ, Lim HJ, Nirula R, Weigelt JA. Length of stay: an appropriate quality measure? Arch Surg. (2007) 142:461-6. doi: 10.1001/archsurg.142.5.461

29. Nijhawan AE, Kitchell E, Etherton SS, Duarte P, Halm EA, Jain MK. Half of 30-day hospital readmissions among HIV-infected patients are potentially preventable. AIDS Patient Care STDS. (2015) 29:465-73. doi: 10.1089/apc.2015.0096

30. Coelho LE, Ribeiro SR, Japiassu AM, Moreira RI, Lara PC, Veloso VG, et al. Thirty-day readmission rates in an HIV-infected Cohort From Rio de Janeiro, Brazil. J Acquir Immune Def Syndromes. (2017) 75:e90-8. doi: 10.1097/QAI.0000000000001352 
31. Berry S, Fleishman J, Moore R, Gebo K. Thirty-day hospital readmissions for adults with and without HIV infection. HIV Med. (2016) 17:167-77. doi: 10.1111/hiv.12287

32. Horwitz L, Partovian C, Lin Z, Herrin J, Grady J, Conover M, et al. Hospital-Wide (All-Condition) 30-Day Risk-Standardized Readmission Measure. Yale New Haven Health Services Corporation; Center for Outcomes Research \& Evaluation (2012). Available online at: https://www. cms.gov/Medicare/Quality-Initiatives-Patient-Assessment-Instruments/ MMS/downloads/MMSHospital-WideAll-ConditionReadmissionRate.pdf (Retrieved September 10, 2011).

33. Joynt KE, Jha AK. Thirty-day readmissions-truth and consequences. New Engl J Med. (2012) 366:1366-9. doi: 10.1056/NEJMp1201598

34. Leppin AL, Gionfriddo MR, Kessler M, Brito JP, Mair FS, Gallacher K, et al. Preventing 30-day hospital readmissions: a systematic review and meta-analysis of randomized trials. JAMA Intern Med. (2014) 174:1095-107. doi: 10.1001/jamainternmed. 2014.1608

35. Jencks SF, Williams MV, Coleman EA. Rehospitalizations among patients in the Medicare fee-for-service program. New Engl J Med. (2009) 360:1418-28. doi: 10.1056/NEJMsa0803563

36. Boccuti C, Casillas G. Aiming for Fewer Hospital U-Turns: The Medicare Hospital Readmission Reduction Program. (2015). Available online at: https:// collections.nlm.nih.gov/catalog/nlm:nlmuid-101707559-pdf

37. Napierala C. Why Compliance Length of Stay (LOS) is the Stronger Outcome Measure Than Crude LOS in DRG Systems. Luzern: Center for Health, Policy and Economics (CHPE); Universität Luzern (2017). doi: 10.13140/RG.2.2.32144.71680

38. Kahn KL, Keeler EB, Sherwood MJ, Rogers WH, Draper D, Bentow SS, et al. Comparing outcomes of care before and after implementation of the DRG-based prospective payment system. JAMA. (1990) 264:1984-8. doi: 10.1001/jama.264. 15.1984

39. Administração Central do Sistema de Saúde (ACSS) (2019). Available online at: http://www.acss.min-saude.pt/

40. Atkins DC, Baldwin SA, Zheng C, Gallop RJ, Neighbors C. A tutorial on count regression and zero-altered count models for longitudinal substance use data. Psychol Addicti Behav. (2013) 27:166-77. doi: 10.1037/a0029508

41. Karazsia BT, Van Dulmen MH. Regression models for count data: illustrations using longitudinal predictors of childhood injury. J Pediatr Psychol. (2008) 33:1076-84. doi: 10.1093/jpepsy/jsn055

42. Hammer TH, Landau JC. Methodological issues in the use of absence data. $J$ Appl Psychol. (1981) 66:574. doi: 10.1037//0021-9010.66.5.574

43. Hall DB. Zero-inflated Poisson and binomial regression with random effects: a case study. Biometrics. (2000) 56:1030-9. doi: 10.1111/j.0006-341X.2000.01030.x

44. Lambert D. Zero-inflated Poisson regression, with an application to defects in manufacturing. Technometrics. (1992) 34:1-14. doi: 10.2307/1269547

Conflict of Interest Statement: The authors declare that the research was conducted in the absence of any commercial or financial relationships that could be construed as a potential conflict of interest.

Copyright (c) 2019 Shaaban and Martins. This is an open-access article distributed under the terms of the Creative Commons Attribution License (CC BY). The use, distribution or reproduction in other forums is permitted, provided the original author(s) and the copyright owner(s) are credited and that the original publication in this journal is cited, in accordance with accepted academic practice. No use, distribution or reproduction is permitted which does not comply with these terms. 